\title{
¿Es elemento una palabra elemental?
}

\author{
PAZ BATTANER ARIAS \\ Universitat Pompeu Fabra
}

Ofrecer un trabajo, por mínimo que sea, a Juan es saber que hay que entrar en su juego de ironías, paradojas, boutades tan solo aparentes, y hacerlo con total seriedad. Me arriesgo a caer en lo que advierte Séneca en sus Epistulae morales ad Lucilium (36.4), «ridícula res elementarius senex», al fijarme en la voz elemento; pero todos los colegas consultados han pensado que era coherente con alguien que ha estudiado con amor la lengua de la Química y que ha actuado como «principio activo» y movilizador en muchos y diferentes ambientes universitarios.

Con esta tesitura entendemos la predicación adjetiva, que la interrogación del título propuesto pone en duda, palabra elemental, como palabra 'sencilla', 'básica', 'fundamental'; pues así interpretamos el adjetivo elemental. Quizá la frase popularizada como característica de Sherlock Holmes, - aunque parece no estar en los originales de Conan Doyle- le asigne también el significado de 'lógica' o, mejor, 'evidente', aunque tras un salto semántico que no es fácil de explicar y que, desde luego los diccionarios no recogen.

0 . La voz elemento tiene una frecuencia variable por épocas y por tipos de textos. El CREA (en consulta de 20 de enero de 2013) ofrece las siguientes frecuencias: para elementos, 21.133 casos de frecuencia absoluta con lo que obtiene un rango 624 y para elemento, 9.053 casos con un rango de 1.594. Este mayor uso del plural sobre el singular del término es una constante en otros estudios estadísticos (Juilland y Chang-Rodríguez 1964, Mark Davies 2006). El Corpus del Nuevo Diccionario Histórico del Español [en adelante CNDHE] de la Fundación Rafael Lapesa permite tener frecuencias absolutas algo más compensadas que las que ofrece el CORDE, pues en su composición se ha tenido en cuenta el criterio de ponderación por periodos. Casos del lema elemento en el CNDHE:

$\begin{array}{ll}\text { Siglos XIII-XV } & 705 \text { casos } \\ \text { Siglo XVI } & 336 \text { casos } \\ \text { Siglo XVII } & 144 \text { casos } \\ \text { Siglo XVIII } & 258 \text { casos } \\ \text { Siglo XIX } & 357 \text { casos } \\ \text { Siglo XX } & 1783 \text { casos }\end{array}$

Se observa bastante homogeneidad en la frecuencia, salvo la bajada correspondiente al siglo XVII y su incremento solo en el último siglo. Los datos, pues, seña- 
lan la presencia del lema elemento en el vocabulario nuclear del español a lo largo del tiempo.

1. Quizá esta voz se presente como trasparente y no problemática por dos características de su valor en todas las épocas. Formalmente es una voz común a todas las lenguas modernas europeas. En lenguas románicas los cognados de elemento son: fr. élément; it. elemento; cat. element; port. elemento. En lenguas de origen germánico coinciden también entre otras: ing. element; al. element; sv. element; flam. element. También se encuentra en lengua eslavas: rus. элемент; pol. elementu; esl. element, etc. Presenta pues una característica propia de los cultismos científicos, como es su internacionalización.

La segunda característica es que, semánticamente, coincide en sus sentidos principales y presenta polisemia en casi todas las lenguas ${ }^{1}$. Se repasará aquí la descripción lexicográfica que se hace de ella, en inglés, en francés y en diccionarios señalados del español, tanto de su significado como de su uso. Bajo esta faceta difícilmente se le puede considerar un cultismo científico hoy.

2. Element, elements en el Oxford English Dictionary [OED] (consulta en línea, 2013-01-12) queda explicado bajo cuatro apartados: I 'componente'; II 'los cuatro elementos'; III 'principio primordial' (marcado como raro); y IV 'letras' (marcado como raro) junto a 'rudimentos de una ciencia'. Estos apartados se desarrollan en catorce acepciones con sus correspondientes subacepciones en donde se colocan los usos especializados de la ciencia y los anticuados. Al final del artículo, la consulta en línea se abre al Middle English Dictionary y se advierte de que la entrada no se ha actualizado desde 1891, indicio quizá de que despierta poco interés.

En el recurso electrónico de Le Grand Robert de la Langue Française [GR], la palabra élément se circunscribe a dos grandes bloques, ambos bajo una descripción común: 'Partie constitutive (d'une chose)'. El primer bloque encierra 'cada una de las cosas cuya reunión o combinación forman otra cosa' y en su información analógica remite a composante, détail, morceau, partie, analyse, división, condition, cause, facteur, principe, critère, donnée, matériau, détail, cellule, para luego especificar en subacepción usos especializados y científicos. El segundo bloque queda enunciado como 'substancia considerada como inanalizable; cuerpo simple del que se forman otros' y además del átomo, y por extensión, se recoge el uso de elementos como representantes de las fuerzas naturales y como 'medio' o 'entorno'.

${ }^{1}$ Elemento presenta una polisemia que contrasta con la precisión que ha desarrollado la voz átomo a lo largo de su historia, analizada por Garriga (2008). 
Parece por lo apuntado que lo extractado de estos grandes diccionarios podría servir para describir el uso de elemento y su plural en lengua española también.

Cuando buscamos la descripción lexicográfica de elemento, elementos en castellano encontramos, naturalmente, semejanzas constatables con lo anteriormente expuesto, aunque la lexicografía más consultada en lengua española tenga, sin serlo, un componente histórico y reconozca significados que difícilmente se encontrarían en uso desde hace más de dos siglos.

El Diccionario de la lengua española [DRAE en línea, consulta 2012-11-25] ordena los sentidos de elemento como 'principio', tanto físico o químico como de la filosofía natural antigua (acepciones 1 y 2), utilizando el definidor principio sin una explicación clara bajo la entrada principio del mismo diccionario. Sigue con 'fundamento' o 'parte integrante de algo' (acepción 3). Luego 'medio' en que se desarrolla un ser vivo (acepción 4); cada 'pieza' de una estructura (acepción 5); 'componente' de una agrupación humana (acepción 6); 'individuo' con valoración positiva o negativa en una acción social (acepción 7). Tras estas siete primeras acepciones vienen las especializadas de Física, Matemáticas y Química; la americana, asignada a Puerto Rico, y ya en plural los sentidos considerados figurados: 'fundamentos y primeros principios de las ciencias' (acepción 12, bastante similar a la $3^{\text {a }}$ ), 'fuerzas naturales' (acepción 13) y también en plural 'recursos, medios' (acepción 14). El diccionario académico recoge también las locuciones, que aquí no interesan, salvo quizá la locución verbal estar alguien en su elemento. El orden de las acepciones se explica observando los cambios que ha sufrido el artículo desde su inserción en Autoridades.

El Diccionario del Español Actual [DEA1999] ofrece, en la agrupación A del artículo correspondiente, tres primeras acepciones no marcadas, 'parte constitutiva', 'componente de una agrupación humana' con uso frecuentemente en singular y sentido colectivo, y 'cosa de las necesarias', también generalmente en plural. La acepción 4, temática, se divide en 'cuerpo simple' y 'principio químico'; en este diccionario este uso de principio sí viene atendido ${ }^{2}$. Las acepciones de 6 a 8 siguen la descripción esperada. La parte $\mathrm{B}$ del artículo se dedica a los figurados, 'individuo' con un complemento calificador o bien por defecto, valor despectivo (acepción 9); y, solo en femenino y coloquialmente, 'prostituta' (acepción 10), una de estas explicaciones ad hoc que el DEA reserva para alguna de sus citas.

${ }^{2}$ Sub principio, 4. Cosa de la que procede [otra (compl de posesión)] | Gambra Filosofía 149: Principio es aquello de lo que algo procede, de cualquier modo que sea. Por eso no todo principio es causa. [Rafael Gambra, Curso elemental de filosofía, $6^{\circ}$ curso, 1963] 
El Diccionario de Uso del Español [DUE 1966] simplifica mucho el artículo correspondiente del DRAE 1956, atribuyendo el significado general de elemento a 'cada una de las partes' o 'cosas de un conjunto', y remitiendo a *parte o *cosa; es decir, colocando a elemento en un nivel muy alto de su cono léxico. Es solo en la segunda edición del CD-ROM, correspondiente a la segunda edición del diccionario [DUE 1998], en la que se introduce un catálogo sui generis con la lista de elementos químicos tal como se conocía por las fechas.

3. Todo lo anterior es explicable por el significado polisémico que elementum

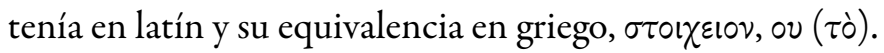

El Oxford Latin Dictionary da para elementum, $-i$ :

1. One of the four substances...|| b. (in general) a component or ingredient. [con citas de a) Cicerón, Ovidio|| b) Plinio Nat. 31.38]

2. (in the Epicurean system) An atom; (in wider use) a particle [Lucrecio, Quintiliano].

3. A letter of the alphabet. [Lucrecio, Suetonio]

4. (pl.) The basic principles of an art or science or of a person's education in general rudiments; (rarely sg.)|| b. the first beginnings, germs, etc. (of a quality, condition or sim.). [a) Cicerón, Lucrecio, Horacio, Quintiliano; b) Ovidio, Estacio, Apuleyo].

Los diccionarios que atienden a las etimologías, como el Ernout-Meillet (2001) dan la equivalencia del griego y su significado nuclear como componente de una fila, 'algo que está en línea', de lo que se desprenden las otras acepciones. En paralelo con el griego, en latín elementa designa las letras como 'rasgos constituyentes' -diríamos hoy- de la sílaba y de la voz, y este significado se generaliza como 'principios de las cosas y de las ciencias'. La etimología propuesta para elemento como /LMN/, segunda serie del alfabeto latino, pudiera ponerse en paralelo con el significado de un abecé castellano o unas beceroles catalanas, lo que parece no ser demasiado convincente. El último diccionario etimológico del latín (de Vaan 2008) ni siquiera recoge elementum como lema y tampoco lo recoge J. F. Niemeyer (1984).

Isidoro utiliza el término en el libro III de la Geometría, pero lo utiliza con el sentido de 'elemento mínimo de las lenguas', lo que identifica con letras. Así: «Sed Hebraei viginti duo elementa litterarum secundum Veteris Testamenti libros utuntur», (III. De litteris communibus). Para después puntualizar «Latini enim inter utramque linguam progredientes viginti tria elementa habent». Pero es en la descripción general del mundo donde sugiere una etimología para elementos y caracteriza el concepto: 
3 Sobre los elementos. 1. Los griegos llaman hile a una especie de materia primera de las cosas, que no está todavía formada, pero que es capaz de admitir todas las formas corporales, y de la que están formados todos los elementos visibles; a partir de su derivación adoptaron este vocablo. Los latinos a esta hile, la denominaron materia, porque todo lo que es informe, y de lo que se hace algo, siempre se llama materia. Por eso los poetas le dieron el nombre de "bosque" y no sin razón, porque las "maderas" provienen de los bosques. 2. A los elementos, los griegos los designan con la denominación de $\sigma \tau \circ \chi \varepsilon \tilde{\imath} \alpha$, porque se integran gracias a una armonía corporativa y a una especie de intercomunión. Se dice que están unidos entre sí por una cierta ligazón natural, hasta el punto de que, si buscamos su origen, partiendo del fuego para llegar a la tierra o a partir de la tierra hasta llegar al fuego, resulta que el fuego se transforma en aire, el aire se condensa en agua, el agua enriquece la tierra; y a su vez la tierra se diluye en agua, el agua se evapora en aire, el aire se debilita hasta convertirse en fuego. 3. En consecuencia, todos los elementos se hallan insertos en todas las cosas, aunque cada una de ellas recibe el nombre del elemento que más abunda en ella. Gracias a la divina providencia todos los elementos se encuentran repartidos entre los propios seres animados: así el Creador llenó de ángeles el cielo; el aire de aves; de peces el mar; y la tierra de hombres y otros seres vivientes. Etimologías, ed. Oroz Reta-Marcos Casquero (1993: 127-129)³.

Parece pues que, remontándose a las primeras descripciones lexicográficas, el significado de elemento, elementos se desarrolla a partir de 'principio, principios' 'Principio', 'fundamento' y 'substancia constitutiva' manteniendo una propiedad común de ligazón en los tres significados nucleares, a partir de los cuales se desarrolla su uso. En los modernos diccionarios del inglés como en Macmillan Collocations Dictionary (2010), se define como «an important basic part of something complicated», para desarrollar después dentro del artículo los adjetivos

${ }^{3} 3$ De elementis. $\Upsilon \lambda \eta \nu$ Graeci rerum quandam primam materiam dicunt, nullo prorsus modo formatam, sed omnium corporalium formarum capacem, ex qua visibilia haec elementa formata sunt; unde et ex eius derivatione vocabulum acceperunt. Hanc $i \lambda \eta \nu$ Latini materiam appellaverunt, ideo quia omne informe, unde aliquid faciendum est, semper materia nuncupatur. Proinde et eam poetae silvam nominaverunt, nec incongrue, quia materiae silvarum sunt. 2 Graeci autem elementa $\sigma \tau \propto \chi \chi \varepsilon \tilde{\alpha} \alpha$ nuncupant, eo quod sibi societatis concordia et communione quadam conveniant. Nam sic ea inter se naturali quadam ratione iuncta dicuntur, [ut] modo originem ab igni repetentes usque ad terram, modo a terra usque ad ignem, ut ignis quidem in aera desinat, aer in aquam densetur, aqua in terram crassescat; rursusque terra diluatur in aquam, aqua rarescat in aera, aer in ignem extenuetur. 3 Quapropter omnia elementa omnibus inesse, sed unumquodque eorum ex eo quod amplius habet accepisse vocabulum. Sunt autem divina providentia propriis animantibus distributa: nam caelum angelis, aerem volucribus, mare piscibus, terram hominibus ceterisque animantibus Creator ipse inplevit. (Isidoro, Etymologiae, XIII, 3). 
incluidos en la definición como tres diferentes acepciones, que se diferencian precisamente por los diferentes tipos de adjetivos con los que se combina.

4. ¿Lo que se describe en los diccionarios se encuentra en los corpus? La consulta en CREA de un lema tan frecuente ha de hacerse por tema. Sobresalen en aportar datos los textos de Ciencias sociales (1679 sing. + 4047 pl.), Política, Economía, Comercio y Finanzas (1854 sing. + 3854 pl.), Artes (1607 sing. + 4068 pl.) y Ciencias y Tecnología (1337 sing. + 3127 pl. ). Le siguen los apartados de Ocio y Salud con más de dos mil formas cada uno. Viene luego el apartado Oral y bajan considerablemente, a unos seiscientos, los apartados de Ficción y Miscelánea ${ }^{4}$.

Elemento aparece en las concordancias como atributo de sustantivos con referente físico; el ilirio es elemento, el agua también; las acciones, bonos, monedas nacionales, etc. son elementos; arco, chimenea, cantería son también atribuidos como elementos, en construcción y arquitectura; un rotor, una supernova o el traje y la droga, por ejemplo, entran dentro de lo que puede atribuirse con elemento cuando se les concibe como constitutivos, integrantes, influyentes o determinantes en alguna circunstancia. De aquí que también se clasifiquen como 'elemento' otros sustantivos colectivos sin referente físico, como la navegación, la televisión, la música, la crítica, la globalización, la relación con Dios, el voto de censura, etc. y mil más. Entre los adjetivos que acompañan al lema elemento en el CREA inciden los que le marcan como 'principio activo y fundamental', matiz que nunca pierde a lo largo del tiempo; entre otros: activo, básico, capaz de, central, clave, crítico, crucial, decisivo, disuasorio, esencial, específico, fundamental, importante, indispensable, inesperado, maestro, motor, necesario, poderoso, práctico, primordial, principal, relevante, sustantivo, sustentador, típico, valioso, vital, etc. Es raro encontrar grupos como: un elemento adicional, un elemento secundario. El sentido de 'primordial' difícilmente lo pierde.

Conviene distinguir la adjetivación directa sobre el sustantivo elemento y la adjetivación indirecta sobre el sustantivo que recibe a su vez el atributo elemento, por ejemplo, en «La agresividad es un elemento creador $\gg$ o «La calle es un elemento agresivo contra él» (CREA ORAL), los adjetivos creador y agresivo adje-

\footnotetext{
${ }^{4}$ Sería interesante estudiar cómo la palabra elemento, proveniente de la Filosofía natural y de la Química moderna, se utiliza hoy más en ciencias sociales que en la ciencia y la tecnología, y que en lengua oral se ha popularizado como indicio de una mentalidad analítica que concibiera la intervención de algún individuo como principio explicativo y determinante de situaciones particulares analizadas ; Un buen elemento!
} 
tivan propiamente a agresividad y a calle. Igual puede pasar con otros adjetivos del tipo disuasorio, estratégico, escaso, etc. Este tipo de construcción podría ser un primer indicio de que elemento, en estos casos, está entrando en un proceso de gramaticalización (Bosque 2001).

En ello inciden también los complementos que pueden recibir elemento o elementos, como de la fiesta, de la tristeza, de corrección, de la polémica, de ayuda, que chocan con la vida cotidiana de la gente, etc. En un diario se puede escribir de un atentado con muerte que «es un elemento de tristeza siempre», aunque estos complementos parecen alejados del significado de 'principio fundamental' y por el contrario cercanos a 'ingrediente', aun dicho de sustantivos sin referente físico.

5. Repasamos ahora su uso a lo largo de los corpus o fuentes diacrónicas en español. Elemento no figura en el Léxico hispánico primitivo (2003), lo cual es esperable dada la temática de los documentos que le sirven de fuente. En el CNDHLE el primer uso lleva el año $1250^{5}$ :

E dos dietas son, una comunal e otra propia: La comunal es, de non comer si non con apetito, e la propia es, de catar el elemento que más vence, e vencer-le con su contrallo (1250, Bocados de oro [CNDHLE]),

para luego aparecer con los cuatro elementos clásicos:

cómmo quando Dios ffizo el mundo, pesó cada cosa por ssí. Et los çielos, que eran más liuyanos, puso de ssuso. Et los elementos que non eran tan ligeros puso sso ellos. Et después el agua e la tierra, que eran más pesados, puso más en ffondón, assí que a cada vno dió su logar ssegunt pesaua (c. 1252-1270. Alfonso X, Setenario [CNDHLE]).

Los elementos aparecen identificados por antonomasia con alguna manifestación de la naturaleza, muy principalmente el agua:

Departe el frayre otrossi que se entiende por ello que homilla dios y abaxa la soberuia y al qui la trae. Et que la somurguia fasta en los auismos de los elementos. Cuemo fue a aquella Reyna somurguiada en los auismos de las aguas (c. 1275, Alfonso X, General Estoria. Segunda parte [CNDHLE]).

Los elementos se ponen en relación con las estaciones del año, con las horas del día también y a través de Galeno con los humores del cuerpo. Y fácilmente aparece elemento como 'ambiente o medio propicio' para algunos seres, siempre atendiendo a los cuatro elementos clásicos:

${ }^{5}$ En el OED element lleva la primera datación en 1300. En el TLF queda registrado en singular en la Séquence de Sainte Eulalie (881) y en la fecha de 1119 como 'principios de la materia'. 
el gamaleón e el topo e el harenc e la salamandra viven en seños elementos de guisa que por mantener sus vidas non toman governamiento ninguno de los otros elementos, si non cadaúno el del suyo, ca el harenc vive dell agua sola, e el gamaleón dell aer, e el topo de la tierra e la salamandra del fuego (c1275, Alfonso X, General Estoria. Segunda parte [CNDHLE]).

La curiosidad de la que sale la especulación sobre los cuatro elementos de la Naturaleza gira sobre qué sea la materia en general, como ya se recogía en Isidoro. Esta preocupación atraviesa muchos siglos.

pero el maestre de Girona dize asy: en prinçipio crio Dios las cosas todas de sin ningun elemento, saluo que crio vna cosa de materia muy delgada inpalpable, saluo que es vna tal massa apareiada para resçebir forma de qualquier cosa, la qual cosa que asy dicho auemos, vnos la llaman el ylle, e otros la llaman la primera materia... (c. 1422-1433, Mose Arragel de Guadalajara, Traducción y glosas de la Biblia de Alba [CNDHLE]).

Por que conviene saber qué cosa es helemento, de lo cual dize Platón en el libro Pachegni - allégalo Alano en la Suma de philosophía-, do dize: «Helemento es la más simple e más pequeña parte de cualquiera parte» $(1428$, Enrique de Villena, Tratado de Astrología [CNDHLE]).

En esta última cita se ve ya la vecindad de elemento con 'átomo', como se leerá también en el Tesoro de Covarrubias, y en este punto requiere también atender a los cuerpos compuestos, elementados.

Ay otra cosa que es indicio e señal en qualquier que cabe fermosura: que los elementos de que es elementada su forma estavan concordes e amigables quando le dixieron bien conpasada proporçión (c. 1444, Juan de Mena, Tratado de amor [CNDHLE]).

El maestro Correas en el Arte de la lengua española castellana (1625) analiza «Antistoixon de anti, i de stoixon, letra, elemento» [CORDE].

Hasta aquí se podría decir que son usos del latín medieval. Alguna novedad se observa en las construcciones con sentidos figurados, por ejemplo, en el adjetivo piadoso que complementa a elemento, como 'principio activo' en una agrupación humana:

Y de aquí podemos saber dónde vino antiguamente que un hombre fuese rey de los otros, ca según dice Julio Solino, que los judíos solían escoger por ley al que veían más sabio y de mejores costumbres, y tal, que a los suyos fuese elemento piadoso, contra los enemigos... (1468, Jardín de nobles doncellas [CNDHLE]).

Algo parecido se lee en: 
...es la razón — según el Philósopho, en el $3^{\circ}$ de Políticas, capítulo $2^{\circ}-$, porque la sustancia de las comunidades, que son los pueblos grandes y ciudades, es engendrada de la multitud o comunidad de las casas o familias, que son el primer o segundo elemento de la ciudad (c. 1527-1550, Bartolomé de las Casas, Apologética historia sumaria [CORDE]).

Con la modernidad y la experimentación surgen dudas sobre su concepción precientífica. Pedro Mejía no entiende que la fuerza de la piedra imán se deba a una cualidad de un elemento, que de por sí no tiene ninguno de los cuatro:

Vemos a la piedra ymán alçar los pedaços de azero y clavos de hierro del suelo, que pesan casi tanto como ella; y la razón escóndesenos y no la sabemos, aunque bien se conosce que aquella calidad no es de elemento ni lo causa el calor del fuego ni la sequedad de la tierra, sino otra fuerça secreta y escondida (1540c. 1550 , Silva de varia lección $[\mathrm{CORDE}])$.

Estas dudas nacen de la discusión sobre cuerpos simples o puros y cuerpos mixtos, en los que predominaría un elemento junto a otros, lo cual llega, usado como tropo, hasta Gracián:

La verdad ordinariamente se ve; extravagantemente se oye; raras veces llega en su elemento puro, y menos cuando viene de lejos; siempre trae algo de mixta de los afectos por donde pasa (1647, Oráculo manual y arte de prudencia [CORDE]).

Para el paso del siglo XVI al XVII, el trabajo que se hace en la Universidad de Salamanca, el DICTER ${ }^{6}$, aporta un artículo sobre elemento con tres acepciones bien diferenciadas: a) Cada una de la cuatro sustancias básicas; b) Fundamentos y principios de las ciencias y artes, bajo la cual se aporta una cita muy reveladora, en la que a elementos se le otorga un sentido de encadenamiento ${ }^{7}$; y c) «Cada una de las piezas o partes integrantes de una estructura» acepción que ofrece una datación relativamente moderna y cuya cita, aunque larga, copio:

En pos de este troço, seguirán todas las municiones y aparatos de guerra que tocaren a la mitad de la provisión y conducta de todo el exérçito, assí de puentes, tablones, puntales y otras qualesquier máquinas, como de pólvora, balas y cuerda, çapas, palas, picos, uñas de cabra, almádenas, cuñas de hierro, marraços, hachas de mano y de golpe, sierras, herrerías y carpinterías, cumplidas de maestros y herramientas, con todo el cumplimiento de la maestrança y es-

\footnotetext{
${ }^{6}$ Agradezco a Ma Jesús Mancho, investigadora principal de este proyecto, su respuesta a mis preguntas sobre el uso de elemento entre los textos que se manejan para la confección de ese diccionario.

${ }^{7}$ La relación de elemento con cadena o encadenamiento se encuentra en varios textos de distinta procedencia, como se verá a continuación.
} 
tado del artillería, y con todas suertes de cordames y clavazón y todo lo demás que deve seguir al traín del artillería, con todos sus elementos y montages (1613, Ufano, Tratado de la Artillería, [DICTER]).

En ella se ve el nuevo sentido de 'pieza' o 'componente' básicos que evidencia el encontrarlo en conjunción con montaje, relación que el DICTER vuelve a mostrar con otra cita del mismo tratado de Artillería y que encontramos en la expresión actual mueble por elementos.

En la consulta al CORDE sobre elemento, elementos en el siglo XVI y XVII, se encuentran muchos textos poéticos y en general literarios, en los que la palabra analizada se muestra metafóricamente. Por ejemplo, como 'ingrediente', «No puede haber buena conversación sin un grano de murmuración, que dicen que es el quinto elemento.» (c. 1550, Juan de Arce, Coloquios de Palatino y Pinciano, CORDE). O Andrenio:

No ai aura más fragante ni que más vivifique que la fama, que tan bien alienta el alma como el cuerpo, y es su puríssimo elemento el airecillo de la honrilla (1657, Baltasar Gracián, El Criticón [CORDE]).

O bien como 'ambiente o medio ambiente':

... de la misma suerte el religioso si se detiene fuera de la celda, o muere o por lo menos (como el pece fuera de su elemento) se resfria, y queda como enagenado del buen propósito (1600, José de Sigüenza, Historia de la Orden de San Jerónimo $[\mathrm{CORDE}])$.

En el Tesoro de Sebastián de Covarrubias, informatizado, se encuentran, entre otras relaciones, las de elemento con átomo, indiviso, indivisible y con cadena:

La trabazón de unas cosas con otras se llama cadena, como es la que tienen entre sí los elementos y todas las cosas criadas que dependen del primer eslabón de su Criador, per quem omnia facta sunt. Desta cadena hicieron mención Homero, Platón, Mercurio Trismegistro (1611, sub cadena, ed. de Arellano).

Este sentido de cadena es el que enlaza con la concepción de 'principio', que remonta al Creador y que explicaría especulativamente la composición sencilla de toda la materia por los cuatro elementos y de la no indivisibilidad de ellos, que estarían indisolublemente cohesionados. Es otro rasgo coincidente con el significado antiguo de 'componente de una fila', 'algo que está en línea'. El artículo de d'Alembert sobre élémens en la Encyclopédie trata elementos como un 'germen' que basta desarrollar encadenadamente para exponer la ciencia con rigor ${ }^{8}$.

${ }^{8}$ Néanmoins quoique dans cette espece de tableau il y ait bien des objets qui nous échappent, il est facile de distinguer les propositions ou vérités générales qui servent de base aux autres, \& dans lesquelles celles-ci sont implicitement renfermées. Ces propositions réunies en un corps, formeront, à 
Es desde finales del siglo $\mathrm{XVII}^{9}$, cuando lo que se identifica con elemento, elementos empieza a ser cuestionado en la Química. Se va abandonando definitivamente la concepción antigua de los cuatro elementos, que quedan exclusivamente como recursos retóricos de ciertos literatos, y se utiliza cada vez más cuerpos simples. Feijoo naturalmente se cuestiona la teoría de los cuatro elementos:

...debemos raciocinar siguiendo el hilo de experiencias sensatas, no de ideales proporciones, como lo hizo Aristóteles en la división de las qualidades elementales, [...]. Lo que ahora digo es que Aristóteles repartió entre los quatro elementos las quatro qualidades, como si fuesse dueño de ellas y de ellos (1728, Benito Jerónimo Feijoo, Theatro crítico universal [CORDE]).

Y ya se lee con normalidad en los textos de Química en español ${ }^{10}$ :

Durante la evaporacion, este fluido, que es un elemento del ácido nitroso, atrae, y vuelve á tomar en el ayre que le rodea, este otro elemento ó principio, que le es preciso para volver á formar este ácido (1791, Luis Proust, Anales del Real Laboratorio de Química de Segovia [CORDE]).

Por ello no es nuevo lo que se lee en la traducción del Diccionario de Física de Mathurin-Jacques Brisson:

*Elementos. Término de Física. Seres simples de que pretenden se componen todos los demás. Los Físicos antiguos contaban quatro Elementos; a saber, la Tierra, el Agua, el Ayre y el Fuego; pero ¿en realidad son elementos estas substancias? (Brisson 1798: 197).

Sigue este Diccionario en su traducción española argumentando como las tierras son sustancias mezcladas de partículas pétreas, salinas, sulfurosas y metálicas. Luego dice del agua:

Despues que Lavoisier, la Place, Monge y Meusnier probaron con innumerables experimentos que el agua no es un ente simple, sino que se compone de diecisiete partes de oxígeno y tres partes de hydrógeno; o lo que es lo mismo de 85 partes de oxígeno y 15 partes de hydrógeno, midiendo por el peso (Véase AGUA); no puede dudarse un solo instante de que el agua no es Elemento, como lo creyeron los Antiguos, que no la llegaron a descomponer (Brisson 1798: 198).

proprement parler, les élémens de la science, puisque ces élémens seront comme un germe qu'il suffiroit de développer, pour connoître les objets de la science fort en détail. (Encyclopédie, sub elémens).

${ }^{9}$ Asimov (1993: 47) dice que a partir de Robert Boyle (1627-1691) cualquier supuesto elemento debería ser examinado con el fin de ver si era realmente simple; si una substancia podía descomponerse en otras más simples, no se trataba de un elemento.

${ }^{10}$ «cuando llegan los primeros profesores a Vergara o a Segovia traen con la nueva ciencia las nuevas denominaciones» (Gutiérrez Cuadrado 2001). Una síntesis histórica del término elemento en su uso químico se encuentra en García Belmar y Bertomeu Sánchez (1999: 52-55). 
Igualmente argumenta del aire y del fuego, para terminar: «No siendo realmente Elementos las substancias que consideraron los Antiguos, es muy probable que haya otras que son verdaderos Elementos, pero que todavía no conocemos y que se descubrirán algún día» (Brisson 1798: 199).

A continuación el Diccionario introduce Elementos DE UN PLANETA, «Llamanse así los principales artículos de su teoría: tales como su longitud; la de su afelio; la de su nodo [...]; todo lo qual se hallará en el Artículo de cada uno». Aquí ya se usa la voz como 'conceptos elementales o fundamentales' para el estudio de los planetas, uso que el siglo XIX registra abundantemente.

Por la vía de la Química, elemento tiene el recorrido esperable, que muestra, por ejemplo, José Muñoz del Castillo (1850-1926) en la publicación en Madrid, Cuadros sinópticos relativos a la clasificación natural (método) de los elementos químicos (1898), en donde se reconoce el esfuerzo por la clasificación de ellos desde William Prout (1785-1850) hasta Julius Lothar von Meyer (1830-1895) y Dmitri Mendeléyev (1834-1907) ${ }^{11}$.

Otro uso aparece en los años finales del siglo XVIII, con la traslación de elemento hacia 'principio activo' en cualquier área del saber, por ejemplo del Derecho nacional:

Estraño mucho que el dotor Alonso de Villadiego, en sus Advertencias al Fuero Juzgo, pág. 7, se atreviesse a llamar el romance de las Partidas i del Fuero Real, mui dificultoso i grosero, siendo claríssimo i puríssimo, i deviendo mayor respeto a las dos más ilustres obras del Derecho de España; pues los quatro libros de Fuero Real son como los elementos; i las Siete Partidas, unas pandectas del Derecho español (1744 Gregorio Mayans y Siscar, Carta a Josef Berní [CORDE]).

Este uso da pie para que con el afán enciclopedista se inste a recoger elementos de todas las ciencias, apoyados naturalmente en el título de las ediciones latinas, o en traducción, de Euclides, que había consagrado el orden deductivo para la exposición de una ciencia ${ }^{12}$. La presencia de Elementos de... en los títulos de manuales de las más diversas materias se documenta abundantemente en las bibliotecas

11 «desde que se organiza la universidad contemporánea (Ley de Claudio Moyano de 1857) y se institucionaliza la Química en la Facultad de Ciencias hasta nuestros días. En este período la química española ha seguido con regularidad, de cerca o de lejos, los ritmos marcados por los centros científicos internacionales» (Gutiérrez Cuadrado 2001).

${ }^{12}$ Pudiera ser este matiz deductivo el que explique el elemental de los comentarios atribuidos a Sherlock Holmes, personaje cuya capacidad inductiva y deductiva es una de sus características más señaladas. 
nacionales de Francia y España a partir del siglo XVII, pero principalmente en el XVIII y en el XIX; este tipo de título se va perdiendo en el XX y en la red ya no se encuentra en documentos actuales ${ }^{13}$. En los títulos se observa bien la diferencia entre el singular y el plural de elemento; en singular caracteriza una influencia determinante, La poesía considerada como elemento de la historia: discurso leído por don José Caveda y Nava, en el acto de su recepción en la Real Academia Española el 29 de febrero de 1852; en plural es donde toma el significado de 'rudimentos' o de 'exposición rigurosa de un saber'.

En el siglo XIX el CORDE ofrece la voz elemento en las más diversas temáticas. En Matemáticas: «El elemento a es el coseno de este ángulo» ${ }^{14}$; en Anatomía, «se compone de un elemento anatómico fundamental que se llama fibra muscular lisa»; Ramón y Cajal también lo utiliza, «Además de los corpúsculos de Golgi que en el ratón de pocos días aparecen poco desarrollados, contiene esta zona, alguno que otro elemento fusiforme, triangular ó estrellado»; en Química y en Geología, «El Flúor, otro de los elementos componentes del globo»; en la divulgación de la Física, «El segundo elemento de un sonido es su intensidad»o la Electricidad se habla de los «elementos componentes» de una pila voltaica; en Botánica, «la célula clorofílica, elemento activo organizador»; en Geografía humana: «se temía el predominio del elemento extranjero en la población argelina»; también en Filología, por ejemplo, «el elemento provenzal, en seguida el italiano, casi al mismo tiempo el latino, más adelante el francés» reina en la poesía castellana.

${ }^{13}$ Como muestran los primeros títulos que se encuentran en la BNE : Levas de la gente de guerra [...] sirve de introducción a los elementos militares o primeros principios de todas las matematicas de que necessita el noble exercicio militar (1647); Elementos de Architectura (1698?); ...elementos de la Typographia (1751); Elementos del arte de escribir para uso de los niños (1753); Elementos de musica para canto (1766); Elementos de lógica y de ethica (1770); La lógica, ó Los primeros elementos del arte de pensar de Etienne Bonnot de Condillac (Madrid 1784); Manual de economía casera; o elementos del gobierno de una casa...(1787). En Francia ocurre lo mismo a partir de Les premiers éléments d'Euclide chrestien (1579), Les éléments de la philosophie morale (1638) y es ilustrativo el artículo de D’Alembert que aprovecha esta voz para hacer un ensayo sobre el método científico, «Le propre d'un bon livre d'élemens est de laisser beaucoup à penser. [...] Des élémens bien faits, suivant le plan que nous avons exposé, \& par des écrivains capables d'exécuter ce plan, auroient une double utilité : ils mettroient les bons esprits sur la voie des découvertes à faire, en leur présentant les découvertes déjà faites; de plus ils mettroient chacun plus à portée de distinguer les vraies découvertes d'avec les fausses; car tout ce qui ne pourroit point être ajoûté aux élémens d'une Science comme par forme de supplément, ne seroit point digne du nom de découverte.»

${ }^{14}$ Las citas que vienen a continuación están todas sacadas del CORDE. 
En todo tipo de exposiciones se puede utilizar el término; por ejemplo, «un elemento característico de los ferrocarriles españoles, es el ancho de su vía»; «La conveniencia del tráfico no es el único elemento que ha de considerarse» para trazar una nueva carretera; en el Ministerio de la Guerra, «los mejores elementos de organización» del ejército no son válidos ante un jefe inepto.

Los elementos unas veces son 'personas', otras 'razones', otras 'influencias', otras 'normas', otras 'células de tejidos biológicos', otras lo que hoy se diría 'estructuras', 'características' o 'componentes', pero difícilmente serían hoy elementos. La palabra en el XIX conquista toda la sociedad y sale del dominio técnico. No es raro leer en los periódicos como elementos las presencias de 'grupos influyentes' en la sociedad:

Allí hay vendedores y traficantes de todo género, productos de diversas industrias, muestras de las mejores ganaderías, gitanos de todas las provincias de España, tabernas y buñolerías en montón: se compra, se vende y se cambalachea; se toca, se come y se bebe; hay palmas, cantares y borracheras más o menos chistosas, pero todo ello como adulterado y compuesto con la mezcla del elemento que llaman elegante y que algunos, tratándose de esta clase de fiestas, se atreverían a calificar de cursi (1870, Gustavo Adolfo Bécquer, Artículos y escritos diversos [CORDE]).

Este uso se manifiesta repetidamente en la crítica política e ideológica. Laureano Figuerola advierte que «no debió olvidarse el elemento individual que cumple, sin estar adscrito al principio de nacionalidad, la ley del trabajo; ni el elemento colectivo...»; Concepción Arenal reconoce que «Muchos y poderosos elementos sociales no están estudiados»; ni desde luego «todos los elementos de que la sociedad se compone» ; lógicamente también está presente la palabra en el Congreso de los Diputados, siempre para 'grupos de sujetos' bien determinados, clerical, democrático, joven, popular, revolucionario, sociales, de la izquierda, etc.:

La junta de Sevilla en el tiempo en que estos gastos enormes se verificaron era un conjunto de tres elementos: el elemento unionista, el progresista y el republicano (Federico Rubio, 24-II-1869, Cortes Constituyentes, Battaner 1977: 397).

Y en los escritos del movimiento obrero:

Tiempo es ya de que no a la locura, a la ambición, a la intriga, sino a la razón, a la ciencia, a la organización obrera, sobre todo, rechazando con energía todo otro elemento de ella extraño, debemos encontrar los destinos de la gran revolución (La Federación, 10-VII-1870, Battaner 1977: 397).

En el siglo XX el uso de elemento se amplia y pierde cada vez más el valor de voz analítica que tenía; sin embargo, no pierde el matiz de 'activo' y 'primordial o 
fundamental', pues difícilmente se puede sustituir por parte. Este matiz de actividad es el detectado en los usos que los diccionarios recogen como 'individuo', el cual no es un uso con capacidad denominativa, sino solo predicativa, siempre con artículo indeterminado: un elemento, benefactor o peligroso, pero nunca el elemento, si no va determinado, como en el elemento ese, que suele tomar tono despectivo.

6. La voz elementun - $i$ valía en latín a 'letras-fonemas' y 'principio originario' (I). De estos valores prosperó el título griego de la obra de Euclides ${ }^{15}$ en plural, que originó los sentidos de 'exposición deductiva de conocimiento' (II) y 'rudimentos de una ciencia' (IIa), que se encontraba en tantas obras didácticas de casi todas las disciplinas; hoy ya muy raramente. De este último sentido se nutre en general, aunque no exclusivamente, el actual adjetivo elemental.

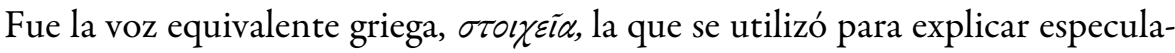
tivamente la materia, el mundo que detectaban los sentidos. Se dictaminó, como ironiza Feijoó, que había cuatro elementos que eran 'principios inanalizables', que abarcaban y explicaban todas las manifestaciones de la naturaleza: la tierra, el agua, el aire y el fuego (III). Estos elementos explicaban la diferencia de seres vivos, de humores, de climas, etc. Había animales que eran exclusivos de alguno de ellos, como los peces del elemento agua o las serpientes del elemento tierra; de aquí generó el valor de 'medio ambiente' (IV) y 'ambiente propicio' (IVa) que hoy perdura lexicalizado en estar en su elemento. La vigencia de la teoría de los cuatro elementos fue de tal envergadura en Occidente que aún se utiliza retóricamente y se encuentran ecos de ella en algunos mensajes que circulan por internet; los elementos como manifestaciones desencadenadas de la naturaleza (IVb).

Lo que Covarrubias (1611) sub elemento explica con un oxímoron, «aquello último en que todas las cosas pueden venir a resolverse, y de donde tomaron principio», en que último y principio desvelan la concepción teocrática (alfa y omega) y especulativa que encierra, se va perdiendo con el tiempo para desvelarse como 'fundamento' (V), y más modernamente como 'cuerpo simple' (Va), 'componente', 'parte constitutiva' (Vb), 'presencia de grupo activo' $(\mathrm{Vc})$, todo lo cual revela el cambio a una concepción científica estructural y ya laica. Con la mentalidad moderna de ciencia empírica, en el siglo XVI se empezó a cuestionar su entidad de 'principio que se resolvía en final'; de ser considerados como inanalizables y de ponerse en relación con los átomos, los elementos pasaron poco a po-

${ }^{15}$ En latín hay una edición en Venecia en 1482, la edición en griego, Basilea 1533, y ya en lenguas vulgares en el siglo XVI, como la de Rodrigo Zamorano en Madrid (1574). 
co, gracias a la Química del siglo XVII y XVIII a multiplicarse en número y a ser considerados 'constituyentes analizables' de la materia. Este largo estadio culmina en el sistema de Dmitri Mendeléyev ${ }^{16}$. Hoy esta voz queda presente en partículas elementales como partículas subatómicas.

Otro deslizamiento semántico ocurrió a partir de este sentido conquistado de 'principios constituyentes' de la materia. Los elementos pudieron dejar de ser 'principios constitutivos' para ser sencillamente 'integrantes fundamentales o básicos de algo considerado complejo' (VI) en un abanico amplio de entidades, actividades o propiedades; y como 'integrantes', sin que el sentido de 'principios' fuera ya necesario, pasan a poder referenciar 'estructuras o partes estructurales' (VIa) de referentes físicos o 'integrantes conceptuales' (VIb) de otros conceptos más inclusivos, como teorías, corrientes de pensamiento, civilizaciones, etc.; y, por otro lado para caracterizar la influencia de las personas ${ }^{17}$ en manifestaciones sociales varias (VII). Diferente, aunque probablemente derivado de este uso, es el que sirve para predicar de 'individuos bien o mal valorados, que muestran su actividad' (VIIa).

Conviene señalar la dificultad lexicográfica de encontrar un definidor adecuado para elemento. Definir elemento siempre ha sido difícil. Se evita el definidor, «elemento es del qual se compone algo... es primero de los componibles y no compuesto» (1551, Martín Cortés Albacar, Breve compendio de la esfera y de la arte de navegar, CORDE). El definidor 'parte' con el que muchos diccionarios lo definen actualmente, no se corresponde bien con el matiz 'activo' y 'fundamental' que

${ }^{16}$ A lo largo del siglo XIX se trabaja en la clasificación períodica de los elementos, lo que culmina en la tabla de Dmitri Mendeléyev. «Nota 1. L'autor distingeix sovint entre elements i cossos simples. Entén per element un àtom que pot estar sol o formant compostos amb altres elements. Entén per cos simple una agrupació d'àtoms, tots iguals» (Mendeléyev, 2005:14). Sobre el giro que esto representa dice Asimov 1993:209) «Por fin se podía sustituir la definición operacional que diera Boyle del concepto "elemento" (como una substancia que no podía descomponerse en substancias más simples) por una definición estructural. La definición de elemento, en el siglo $\mathrm{XX}$, sería: un elemento es una substancia que se compone de átomos que poseen todos un número atómico idéntico y característico».

${ }^{17}$ En TLF : [...] B.- - Partie concourant fonctionnellement à constituer un ensemble unitaire lié à une activité humaine. [...]

2. [L'ensemble unitaire est de nature sociale; l'élément est une pers. ou un groupe de pers.] Toute fraction d'un ensemble constitué par l'association naturelle ou conventionnelle d'êtres humains.

a) Au sing. ou au plur. Membre de tel ensemble donné. « Les huguenots français constituaient ici, comme dans toute l'Amérique, les meilleurs éléments de l'immigration » (MORAND, New-York, 1930, p. 11). [...] 
se mantiene hasta en los usos que parecen más cercanos a 'parte', como en elementos de arquitectura referido a fragmentos aprovechables de otras construcciones.

7. ¿Cómo se puede caracterizar semánticamente una palabra como elemento, elementos?

De ser una voz con referentes concretos en el área del saber, pasa a ser un concepto cercano a los considerados primitivos semánticos. Sin embargo no se encuentra en Wierzbicka (1996), donde se reconoce como primitivos semánticos part (of) y kind (of). En el capítulo Semantic Primitives and Semantic Fields hay un apartado en que se distinguen 'clases culturales' y 'clases naturales' (Wierzbicka 1996: 172); otro en que se advierte de la diferencia entre significado y conocimiento, (Wierzbicka 1996: 262), o bien entre polisemia y vaguedad y entre concretos y abstractos (Wierzbicka 1996: 337); en todos podría colocarse el significado de elemento. Se ronda el problema, pero la voz no aparece.

La polisemia de elemento responde difícilmente a algún quale de los establecidos por Pustejovsky para la polisemia regular (Pustejovsky 1995:85 y ss.). Quizá desde la consideración del quale agentivo, el sentido de los fonemas representados en el alfabeto, letras, se actualizó como 'principio' con referencia a un agente todopoderoso y como 'cadena', para posteriormente, ser una variedad 'fundamental' de meronimia. Atendiendo al quale funcional solo ha tenido desarrollo como metáfora de manifestaciones de la naturaleza o de individuos con alguna incidencia en grupos humanos, y, de aquí, a ser una palabra con valoración adherida, es decir, predicativa.

La semántica cognitiva atiende la incorporación de valores culturales al significado. Elemento es una voz proteica que se puede encuadrar en varios marcos de conocimiento. La teoría psicológica del prototipo, la concepción de la metáfora conceptual, los modelos cognitivos idealizados y la contribución a la teoría del cambio de significado, difícilmente ubican una palabra como elemento. El estereotipo social, el conocimiento y uso de una palabra compartido por los hablantes de una misma comunidad lingüística (Putnan 1975), es muy amplio para esta voz. En el caso de elemento la comunidad sobrepasa varias lenguas. Elemento ha sido y es un instrumento útil y habitual en el nicho de pensamiento en el que estamos, como expresó Matoré hace ya muchos años ${ }^{18}$.

8. La atención por el vocabulario científico-técnico se detiene habitualmente en las novedades léxicas que aporta. Se trata del avance de la ciencia, de la innovación técnica y de los nuevos paradigmas científicos que delatan esos neologismos.

${ }^{18}$ «Le mot est un outil de compréhension sociale» (Matoré 1953: 39). 
Interesa el cuándo, cómo y por qué las voces de la ciencia aparecen y si se forjan con recursos patrimoniales o se introducen por cultismo o préstamo; y si esto ocurre en paralelo con la Ciencia y con la historia que han vivido sus hablantes. El seguimiento de los más de cincuenta años del siglo XIX que hubo de pasar para lograr asentar los términos del sistema métrico decimal en el español (Gutiérrez Cuadrado y Peset 1997) muestra bien la lucha y la constancia que requieren algunas de las novedades y los nuevos términos que las visten para implantarse cuando otros están arraigados. Sin embargo hay otras voces que se hunden en las preocupaciones científicas despertadas en el Mediterráneo oriental en torno al siglo VI a. C., que han convivido hasta hoy de una manera callada con las lenguas conocidas como occidentales, logrando una adaptación camaleónica. Sin estos términos, sin embargo, el discurso científico-técnico no hubiera podido desarrollarse en casi ninguna de las ramas en que el saber se ha ido especializando poco a poco. Uno de estos términos es elemento, elementos, y desde esta perspectiva es una palabra elemental.

La historia de la ciencia y su formulación lingüística presentan momentos estelares y largas épocas interestelares; a estas últimas pertenece la voz elemento.

\section{REFERENCIAS BIBLIOGRÁFICAS}

\section{DICCIONARIOS Y CORPUS}

CNDHLE = Corpus del Nuevo Diccionario Histórico de la Lengua Española, Fundación Rafael Lapesa, Real Academia Española, http://web.frl.es/CNDHE/view/inicioExterno.view.

CORDE = Corpus Diacrónico del Español, Real Academia Española, http://corpus.rae.es/cordenet.html.

CREA = Corpus de Referencia del Español Actual, Real Academia Española, http://corpus.rae.es/creanet.html.

DEA = Seco, Manuel, dir., Olimpia Andrés y Gabino Ramos (1999): Diccionario del Español Actual, Madrid, Aguilar, 2 vols.

DRAE = Diccionario de la Lengua Española: Real Academia Española, http://lema.rae.es/drae/.

DUE = Moliner, María: Diccionario de Uso del Español, ed. en CD Rom, versión 2.0., Madrid, Gredos, 2001.

Encyclopédie = L'Encyclopédie de Diderot et d'Alembert, ou, Dictionnaire raisonné des sciences, des arts et des métiers, Marsanne, Redon, CD Rom version 1.01 [2000]; también http://encyclopédie.eu/html. 
Ernout-Meillet = Alfred Ernout y Antoine Meillet, Dictionnaire étymologique de la langue latine: histoire des mots, $4^{\mathrm{a}}$ ed. augm. D'additons et de corrections nouvelles par Jacques André, Paris, Klincksieck, 1985.

Etymologiae-Etimologías = Isidoro de Sevilla, ed. José Oroz Reta y Manuel-A. Marcos Casquero, Madrid, BAC, 1993, 2 vols.

GR = Le Grand Robert de la Langue Française, Alain Rey, dir., Paris, Dictionnaires Le Robert, 2ème ed., versión electrónica, [2007?].

OED = Oxford English Dictionary on line, Oxford, Oxford University Press, 2001.

Oxford Latin Dictionary, Oxford, Oxford University Press, 2012.

TLF = Trésor de la Langue Française, Paul Imbs y Bernard Quemada, dirs., CD Rom text intégral, Paris, CNRS Éditions, 2000.

\section{OBRAS CITADAS}

Asimov, Isaac (1993 trad. española): Breve historia de la Química: introducción a las ideas y conceptos de la Química, Madrid, Alianza Editorial.

Battaner, M. Paz (1977): Vocabulario político-social en España (1868-1873), Madrid, Anejos del BRAE XXXVII.

BOSQUE, Ignacio (2001): «On the Weight of Light Predicates», en J. Herschensohn, E. Mallen y K. Zagona, eds., Features and Interfaces in Romance: Essays in Honor of Heles Contreras, Amsterdam, John Benjamins, pp. 23-38.

BRISSON, Mathurin-Jacques (1798): Diccionario universal de Física, tomo IV, E / escrito en francés por Brisson; traducido al castellano, con los nuevos descubrimientos posteriores á su publicación por los Doctores D. C. C. [Cristóbal Cladene] y D. F. X. C. Madrid, Imprenta Real. http://babel.hathitrust.org/cgi/pt?id=ucm.5310800314; view=1up;seq=209.

Covarrubias Horozco, Sebastián de (1611): Tesoro de la lengua castellana o española, edición conjunta con el Suplemento y los añadidos de Noydens, Ignacio Arellano y Rafael Zafra, eds., Madrid, Universidad de Navarra-Iberoamericana. CDRom Studiolum, 2006.

DAVIES, Mark (2006): A Frequency dictionary of Spanish: core vocabulary for learners, Nueva York-Londres, Mouton.

EUCLIDES (1739): Elementos geometricos de Euclides: dispuestos en methodo breve, y facil, para mayor comodidad de los aficionados, y uso del Real Seminario de Nobles de Madrid por Gaspar Álvarez (S. I.), Madrid, en la Oficina de la calle Angosta de San Bernardo.

García Belmar, Antonio (1999): Nombrar la materia: una introducción histórica a la terminología química, Barcelona, Ediciones del Serbal.

Garriga, Cecilio (1998): «El Diccionario Universal de Física de Brisson (1796-1802)», en C. García Turza, F. González y J. Mangado, eds., Actas del IV Congreso Internacional de Historia de la Lengua Española, Logroño, AHLE-Gobierno de La Rioja-Universidad de La Rioja, pp. 179-190.

- (2008): «Notas sobre la historia de la voz átomo», Revista de Investigación Lingüística, 1 , pp. $95-124$. 
- y Francesc RODRÍGUEZ (2006): «La lengua de la ciencia y la técnica moderna en el CORDE: Los Anales de Química de Proust», en E. Bernal y J. DeCesaris, eds., Palabra por palabra. Estudios ofrecidos a Paz Battaner, Barcelona, IULA-UPF, pp. 219-232.

GUTIÉRREZ CUADRADO, Juan (2001): «Lengua y ciencia en el siglo XIX español: el ejemplo de la Química», en M. Bargalló, E. Forgas, C. Garriga, A. Rubio y J. Schnitzer, eds., Las lenguas de especialidad y su didáctica, Tarragona, Universitat Rovira i Virgili, pp. 181196.

— y José Luis PESET (1997): Metro y Kilo, El sistema Métrico Decimal en España, Madrid, Akal.

JuIlland, Alphonse y Eugenio CHANG-RodRíGueZ (1964): Frequency dictionary of Spanish words, Londres, Mouton.

LAPESA, Rafael y Constantino GARCía (2003): Léxico hispánico primitivo, al cuidado de Manuel Seco, Madrid, Fundación Menéndez Pidal-Real Academia Española.

Matore, Gustave (1953): La Méthode en Lexicologie (Domaine Français), París, Didier.

MENDELÉYEV, Dmitri Ivanovich (2005 trad. catalana): La Relació entre les propietats dels elements i llur pes atómic, Barcelona, Societat catalana de Química.

NIEMEYER, Jan Frederik (1984): Mediae latinitatis lexicon minus: lexique latin médiévalfrançais/anglais = a medieval latin-french/english dictionary, Leiden, E. J. Brill.

Pustjovsky, James (1995): Generative Lexicon, Cambridge (Mass.), MIT Press.

Putnam, Hilary (1975): Mind, language and reality, Cambridge, Cambridge University Press.

RUNDELL, Michael y Gwyneth FoX, eds. (2010): Macmillan Collocations Dictionary, Oxford, Macmillan Education.

VAAN, Michiel Arnoud Cor de (2008): Etymological dictionary of Latin and the other Italic languages, Leiden-Boston, Brill.

WiERZBICKA, Anna (1985): Lexicography and conceptual analysis, Ann Arbor (Mich.), Karoma. 